\title{
A Novel Sensor for In Situ Detection of Freeze-Thaw Characteristics in Plants from Stem Temperature and Water Content Measurements
}

\author{
Chao Gao $\mathbb{D}^{1,2}$ Hao Tian $\mathbb{D}^{1,2}$ and Yandong $\mathrm{Zhao}^{3,4}$ \\ ${ }^{1}$ School of Artificial Intelligence, Beijing Technology and Business University, Beijing 100048, China \\ ${ }^{2}$ Beijing Key Laboratory of Big Data Technology for Food Safety, Beijing Technology and Business University, Beijing 100048, China \\ ${ }^{3}$ School of Technology, Beijing Forestry University, Beijing 100083, China \\ ${ }^{4}$ Beijing Laboratory of Urban and Rural Ecological Environment, Beijing Municipal Education Commission, Beijing 100083, China
}

Correspondence should be addressed to Hao Tian; thc_1015@foxmail.com

Received 22 October 2020; Revised 21 January 2021; Accepted 28 January 2021; Published 15 February 2021

Academic Editor: Jingwei Wang

Copyright (c) 2021 Chao Gao et al. This is an open access article distributed under the Creative Commons Attribution License, which permits unrestricted use, distribution, and reproduction in any medium, provided the original work is properly cited.

Freezing is a typical abiotic stress on plants, which can induce physiological damages of plants. A better understanding of plant freeze-thaw characteristics contributes to solving some hot issues in plant physiology, such as cold resistance and cold acclimation. This article presents a novel sensor for in situ detection of freeze-thaw characteristics in plants based on stem temperature and water content. The measuring circuit of stem temperature was designed based on constant current source and platinum resistance. The measuring circuit of stem water content was designed based on standing wave ratio and the dielectric properties of stem tissue. The temperature resolution of the compound sensor is less than $0.1^{\circ} \mathrm{C}$. The MAE and RMSE of temperature measurement are approximately $0.57^{\circ} \mathrm{C}$ and $0.65^{\circ} \mathrm{C}$, respectively. The volumetric water content resolution of the compound sensor is less than $0.05 \%$. The MAE and RMSE of volumetric water content measurement are approximately $1.59 \%$ and $1.81 \%$, respectively. Moreover, a mathematical model for describing the freeze-thaw characteristics of plant stem was established and solved based on the compound sensor. Then, some freeze-thaw indicators including stem water content, ice content, freezing depth, freezing velocity, thawing depth, and thawing velocity were solved and used to interpret the freeze-thaw rules of plant stem. It can be concluded that the freeze-thaw velocity is closely related to the physicochemical properties of plant stem which also change dynamically in the freeze-thaw cycle.

\section{Introduction}

Freezing is a typical abiotic stress on plants. From the microperspective, freezing stress can induce various damages for plants, such as cellular dehydration, structural changes in tissues or organs, and embolisms in xylem vessels $[1,2]$. From the macroperspective, freezing stress can inflict the reduction of crop yields and limit the distribution of plant species $[3,4]$. Therefore, it is significant to accurately detect freeze-thaw characteristics which can quantify freezing stress on plants.

Some early detection methods of freeze-thaw characteristics in plants were indirect and assumed that plant tissue fluid had freeze-thaw properties of ideal solutions [5]. Ideal freezethaw curves can be calculated by measuring cell solute con- centrations, hydrostatic pressures, and the amounts of bound water [6]. With the development of electronic detection technology, some of direct detection methods have been used to study freeze-thaw characteristics in plants, mainly including calorimetric method, spectrometric method, and electron microscopy. Calorimetric method basically involves the detection of exothermic and endothermic events by monitoring relative temperature changes in plant tissue fluid. Based on different thermal analysis techniques, common calorimetric methods include conventional thermal analysis, differential thermal analysis (DTA) [7], and differential scanning calorimetry (DSC) [8]. Conventional thermal analysis is primarily used to determine the freezing and thawing points of plant tissue fluid by inserting a thermocouple in a stem and 
monitoring stem temperature during freeze-thaw cycles. Compared with conventional thermal analysis, DTA has a higher resolution of temperature by comparing the output from two thermocouples inserted in a sample and reference $[3,4]$. Combined with the heat of fusion of water and the heat capacities of water and ice, DSC can quantify the amount of frozen or thawed water by measuring differences in heat evolution or absorption between the sample and reference during freeze-thaw cycles. But it is difficult to choose the correct heat of fusion and heat capacity for plant tissue fluid, thus limiting the further application of DSC. Based on different spectral bands, common spectrometric methods include infrared video thermography (IRVT) [9], nuclear magnetic resonance (NMR) [10], and magnetic resonance imaging (MRI) [11]. Compared with the above calorimetric methods, IRVT can provide a real-time heat map of the temperature of the plant surface, thus revealing the distribution and evolution of ice. NMR provides a method to quantify the liquid water content of partially frozen plant tissues. In contrast, MRI is a major improvement to NMR and has sufficient resolution to observe liquid water in the dimension of plant tissues or organs. Based on different treatment processes, common electron microscopy methods include cryoscanning electron microscopy (CSEM) [12] and freeze-substitution electron microscopy (FSEM) [13]. CSEM shows ice by the appearance of fracture faces during the sublimation process of ice. FSEM shows ice by the appearance of cavities during the dissolution process of ice. Both methods have sufficient resolution to identify ice in the dimension of cells or molecules.

These methods differ greatly in temporal resolution: calorimetric method $>$ spectrometric method $>$ electron microscopy. And the calorimetric methods can realize in situ measurement of the freezing and thawing points of plant tissue fluid. However, the disadvantage of calorimetric methods is that it is difficult to quantify the amount of freezing or thawing that takes place. In the meanwhile, considering that the measuring method of standing wave ratio has been used to quantify stem water content with high performance [14], hence, a novel method combining calorimetric method and standing wave ratio was proposed to detect the freeze-thaw characteristics of plant stem in this study. The main research contents in this paper are as follows: (1) developing a compound sensor for detecting stem temperature and water content, (2) analyzing the measurement performance of the compound sensor, (3) establishing a mathematical model for describing the freeze-thaw characteristics of plant stem, and (4) interpreting the freeze-thaw characteristics of plant stem based on the freeze-thaw model.

\section{Materials and Methods}

2.1. Measuring Principle of Stem Temperature. The measuring circuit of stem temperature was designed based on constant current source and platinum resistance [15]. As illustrated in Figure 1, initially, the reference voltage $V_{\text {ref }}$ is converted to the constant current source with the value of $V_{\text {ref }} / R_{\text {ref }}$ via the operational amplifier $\mathrm{U} 1$ and the reference resistance $R_{\text {ref }}$. As the current $I$ flows through the platinum resistance $R_{\mathrm{Pt} 100}$, a tiny voltage difference is generated on $R_{\mathrm{Pt} 100}$. Ultimately, the tiny voltage difference is amplified into the standard voltage output signal $V_{\text {out }}$ by the operational amplifier U2. Hence, the output of stem temperature measuring circuit can be calculated by

$$
V_{\text {out } 1}=\beta_{2} I R_{\mathrm{Pt} 100}=\frac{\beta_{2} V_{\text {ref }} R_{\mathrm{Pt} 100}}{R_{\mathrm{ref}}}
$$

where $\beta_{2}$ is the amplification coefficient of the operational amplifier U2.

There is a linear relationship between $R_{\mathrm{Pt100}}$ and the temperature $T$, which can be expressed as

$$
T=k R_{\mathrm{Pt} 100}+b
$$

where $k$ is the proportionality coefficient and $b$ is the bias coefficient. In accordance with Formula (1), Formula (2) can be rewritten as

$$
T=\frac{k R_{\text {ref }}}{\beta_{2} V_{\text {ref }}} V_{\text {out1 }}+b
$$

As the parameters including $R_{\text {ref }}, V_{\text {ref }}, \beta_{2}, k$ and $b$ are determined, it can be concluded from Formula (3) that the stem temperature can be calculated by measuring the output voltage of $\mathrm{U} 2$.

\subsection{Measuring Principle of Stem Volumetric Water Content.}

The measuring circuit of stem water content was designed based on standing wave ratio [16] and the dielectric properties of stem tissue [17]. As illustrated in Figure 2, initially, a high-frequency electromagnetic wave generated by the $100 \mathrm{MHz}$ oscillator spreads along the transmission line. But there is an impedance mismatch between the impedance of the transmission line $Z_{0}$ and the impedance of the annular electrodes $Z_{l}$, causing partial incident wave to be reflected back towards the source. Then, the incident wave and the reflected waveform a stable standing wave on the transmission line. Both terminal voltages of the transmission line $V_{a}$ and $V_{b}$ are measured by two wave detectors separately. Ultimately, the voltage difference between $V_{a}$ and $V_{b}$ is amplified into the standard voltage output signal $V_{\text {out2 }}$ by the operational amplifier U. Hence, the output of stem water content measuring circuit can be calculated by

$$
V_{\text {out } 2}=\beta\left(V_{a}-V_{b}\right)=2 \beta A \rho=2 \beta A \frac{\left(Z_{l}-Z_{0}\right)}{\left(Z_{l}+Z_{0}\right)}
$$

where $\beta$ is the amplification coefficient of the operational amplifier $\mathrm{U}, A$ is the amplitude of the oscillator, and $\rho$ is called the reflection coefficient.

As the parameters including $\beta, A$, and $Z_{0}$ are determined, it can be concluded from Formula (4) that the impedance of the annular electrodes $Z_{l}$ can be calculated by measuring the output voltage of $U$. Since stem water content mainly depends on $Z_{l}$, it can be derived from $V_{\text {out2 }}$ based on a 


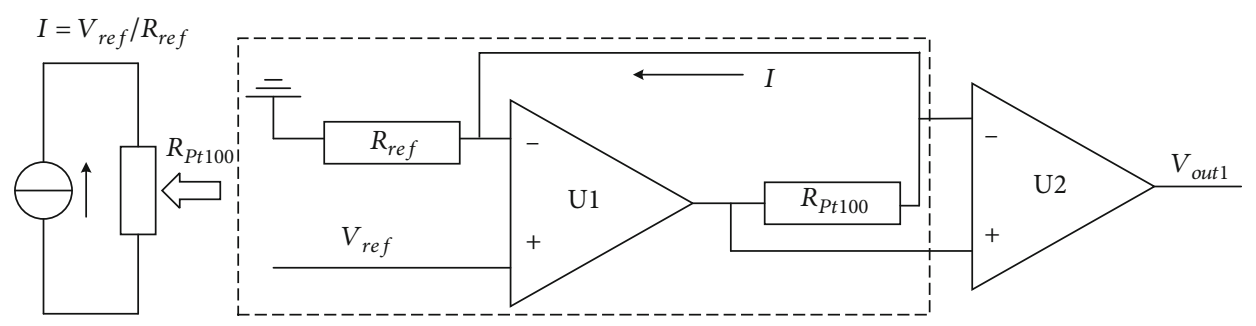

FIGURE 1: Schematic diagram of stem temperature measuring circuit.

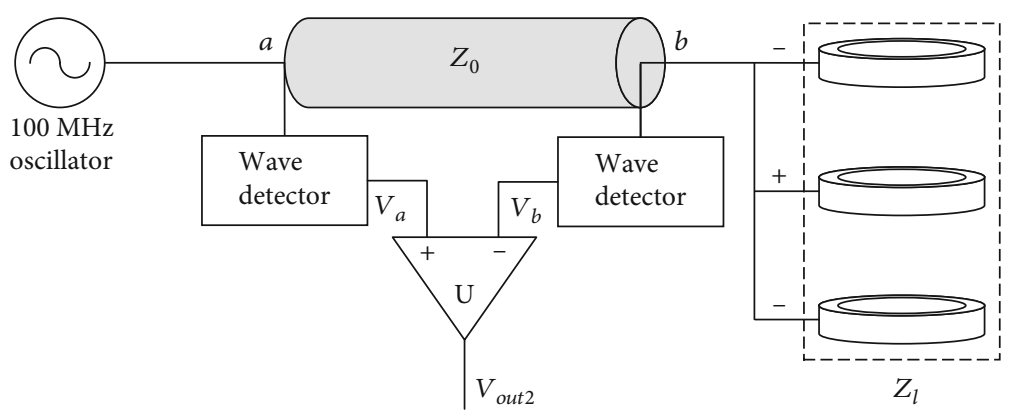

FIgURE 2: Schematic diagram of stem water content measuring circuit.

definite function which can be obtained by drying calibration method.

2.3. Measuring Electrodes of the Compound Sensor. In the structure diagram of measuring electrodes shown in Figure 3(a), stem temperature electrodes are composed of two stainless-steel probes with embedded Pt100 platinum resistance. The diameter of the probe is set to $1 \mathrm{~mm}$ to reduce the damages to stem tissue, and the length of the probe can be customized according to stem diameter. Stem water content electrodes consist of three elastic stainless-steel rings, the diameter of which can be customized according to stem diameter and adapt to the changes of stem growth. The thickness and width of the ring are $0.2 \mathrm{~mm}$ and $8 \mathrm{~mm}$, respectively. The lower and upper electrodes are negative, and the middle electrode is positive. The spacing of adjacent electrodes is $10 \mathrm{~mm}$. In the material object of measuring electrodes shown in Figure 3(b), the stainless-steel probe is inserted into the elastic stainless-steel ring through a connector. The installation process of the compound sensor is divided into three steps. First, the connection position between the compound sensor and the stem is polished into a standard ring. Second, a mounting hole with a diameter of $1 \mathrm{~mm}$ is drilled in the stem. Third, the probe is knocked into the sapwood by a rubber hammer, and the elastic ring is snugly wrapped around the stem.

2.4. Hardware System of the Compound Sensor. The hardware system of the compound sensor mainly consists of detection units and collection units. As shown in Figure 4(a), detection units include temperature detection unit and water content detection unit, and the other functional units can be collectively called collection units. The high-performance microcontroller STM32 was chosen as the hardware platform.
The 12-bit analog-to-digital converter with a reference voltage of $3.3 \mathrm{~V}$ can achieve the sampling of two detection units at the resolution of $0.8 \mathrm{mV}$. The technique of time-sharing power supply was adopted to avoid the electromagnetic interference between two detection units. The compound sensor can communicate with upper-computer software through the RS485 interface. Moreover, the measured data can be stored on a local SD card and transmitted to a remote server through the GPRS module. As shown in Figures 4(a) and 4(c), the printed circuit boards of detection and collection units were designed separately according to the hardware system of the compound sensor.

2.5. Freeze-Thaw Model of Plant Stem. In order to quantify the freeze-thaw characteristics of plant stem through the compound sensor, the freeze-thaw model of plant stem was established according to the physical structure of plant stem. Then, some freeze-thaw indicators were defined and derived based on the freeze-thaw model. The volumetric ice content $\theta_{\text {ice }}$ of the stem can be calculated by

$$
\begin{aligned}
\theta_{\text {ice }} & =\frac{m_{\text {ice }}}{\rho_{\text {ice }} V_{\text {stem }}} \\
& =\frac{\rho_{\text {liquid }}\left(\theta_{\text {threshold }}-\theta_{\text {liquid }}\right) V_{\text {stem }}}{\rho_{\text {ice }} V_{\text {stem }}} \\
& =\frac{\rho_{\text {liquid }}\left(\theta_{\text {threshold }}-\theta_{\text {liquid }}\right)}{\rho_{\text {ice }}},
\end{aligned}
$$

where $m_{\text {ice }}$ is the ice mass in stem, $\rho_{\text {ice }}$ is the ice density $\left(0.9 \mathrm{~g} \mathrm{~cm}^{-3}\right), \rho_{\text {liquid }}$ is the water density $\left(1 \mathrm{~g} \mathrm{~cm}^{-3}\right), \theta_{\text {threshold }}$ is the initial volumetric water content of stem at the critical freezing temperature at which stem tissue fluid begins to 


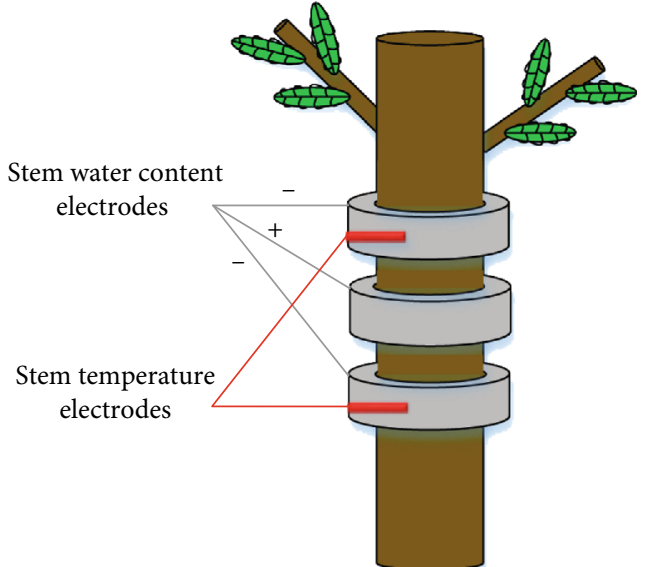

(a)

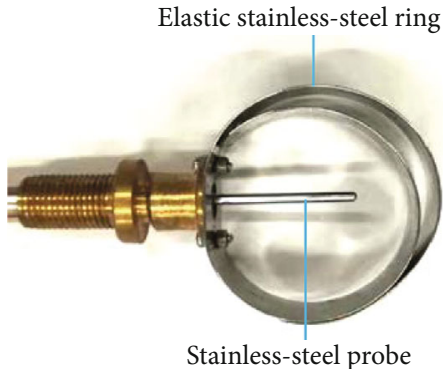

(b)

Figure 3: (a) Structure diagram of measuring electrodes. (b) Material object of measuring electrodes.

freeze, $\theta_{\text {liquid }}$ is the volumetric water content of stem during the freezing process, and $V_{\text {stem }}$ is the volume of the stem.

Considering that the stem usually consists of multiple growth rings with different radius and wood in the same growth ring has the same physicochemical properties, it can be assumed that the stem segment is a cylinder and the water in stem freezes or thaws evenly from the outer growth ring to the inner growth ring. According to the freezing model of stem segment shown in Figure 5(a), the volume of stem segment $V_{\text {stem }}$ and the ice volume $V_{\text {ice }}$ in stem segment can be expressed by

$$
\begin{gathered}
V_{\text {stem }}=\pi R_{\text {stem }}^{2} L_{\text {stem }}, \\
V_{\text {ice }}=\frac{m_{\text {ice }}}{\rho_{\text {ice }}}=\frac{\rho_{\text {liquid }} \pi\left(R_{\text {stem }}^{2}-R_{\text {UFA }}^{2}\right) L_{\text {stem }} \theta_{\text {threshold }}}{\rho_{\text {ice }}},
\end{gathered}
$$

where $R_{\text {stem }}$ is the radius of stem segment, $L_{\text {stem }}$ is the length of stem segment, and $R_{\mathrm{UFA}}$ is the radius of the unfrozen area. According to Formula (6) and (7), $\theta_{\text {ice }}$ can be rewritten as

$$
\theta_{\text {ice }}=\frac{V_{\text {ice }}}{V_{\text {stem }}}=\frac{\rho_{\text {liquid }}\left(R_{\text {stem }}^{2}-R_{\mathrm{UFA}}^{2}\right) \theta_{\text {threshold }}}{\rho_{\text {ice }} R_{\text {stem }}^{2}} .
$$

The radius of the unfrozen area $R_{\mathrm{UFA}}$ can be derived based on Formula (5) and (8), and

$$
R_{\mathrm{UFA}}=R_{\text {stem }} \sqrt{1-\frac{\rho_{\text {ice }} \theta_{\text {ice }}}{\rho_{\text {liquid }} \theta_{\text {threshold }}}} .
$$

The freezing depth of stem segment $D_{\text {freeze }}$ was defined as the difference between $R_{\text {stem }}$ and $R_{\mathrm{UFA}}$. The freezing velocity of stem segment $v_{\text {freeze }}$ was defined as the variation of $D_{\text {freeze }}$ per unit time. The two indicators of freezing information can be calculated by

$$
\begin{gathered}
D_{\text {freeze }}=R_{\text {stem }}-R_{\mathrm{UFA}}=R_{\text {stem }}\left(1-\sqrt{1-\frac{\rho_{\text {ice }} \theta_{\text {ice }}}{\rho_{\text {liquid }} \theta_{\text {threshold }}}}\right), \\
v_{\text {freeze }}=\frac{\Delta D_{\text {freeze }}}{\Delta t},
\end{gathered}
$$

where $\Delta D_{\text {freeze }}$ is the variation of $D_{\text {freeze }}$ at the interval of $\Delta t$.

The thawing model of stem segment was established and analyzed in the same way as the freezing model. According to the thawing model of stem segment shown in Figure 5(b), the ice volume $V_{\text {ice }}$ in stem segment can be expressed by

$V_{\text {ice }}=\frac{m_{\text {ice }}}{\rho_{\text {ice }}}=\frac{\rho_{\text {liquid }} \pi\left[\left(R_{\text {stem }}-D_{\text {thaw }}\right)^{2}-R_{\text {UFA }}^{2}\right] L_{\text {stem }} \theta_{\text {threshold }}}{\rho_{\text {ice }}}$,

where $D_{\text {thaw }}$ is the thawing depth of stem segment. According to Formula (6) and (11), $\theta_{\text {ice }}$ can be rewritten as

$$
\theta_{\text {ice }}=\frac{V_{\text {ice }}}{V_{\text {stem }}}=\frac{\rho_{\text {liquid }}\left[\left(R_{\text {stem }}-D_{\text {thaw }}\right)^{2}-R_{\text {UFA }}^{2}\right] \theta_{\text {threshold }}}{\rho_{\text {ice }} R_{\text {stem }}^{2}} .
$$

The quadratic equation with one variable about $D_{\text {thaw }}$ can be derived based on Formula (5) and (12), and

$$
D_{\text {thaw }}^{2}-2 R_{\text {stem }} D_{\text {thaw }}+\left(1-\frac{\rho_{\text {ice }} \theta_{\text {ice }}}{\rho_{\text {liquid }} \theta_{\text {threshold }}}\right) R_{\text {stem }}^{2}-R_{\text {UFA }}^{2}=0
$$




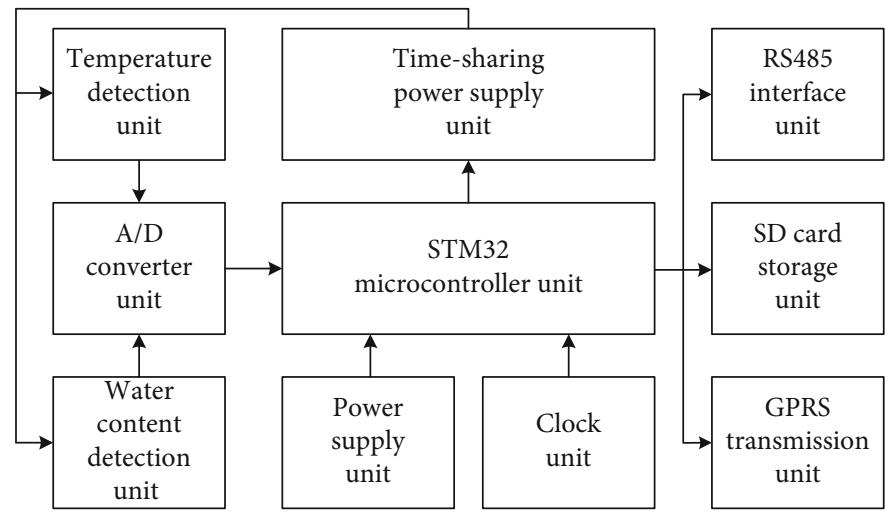

(a)

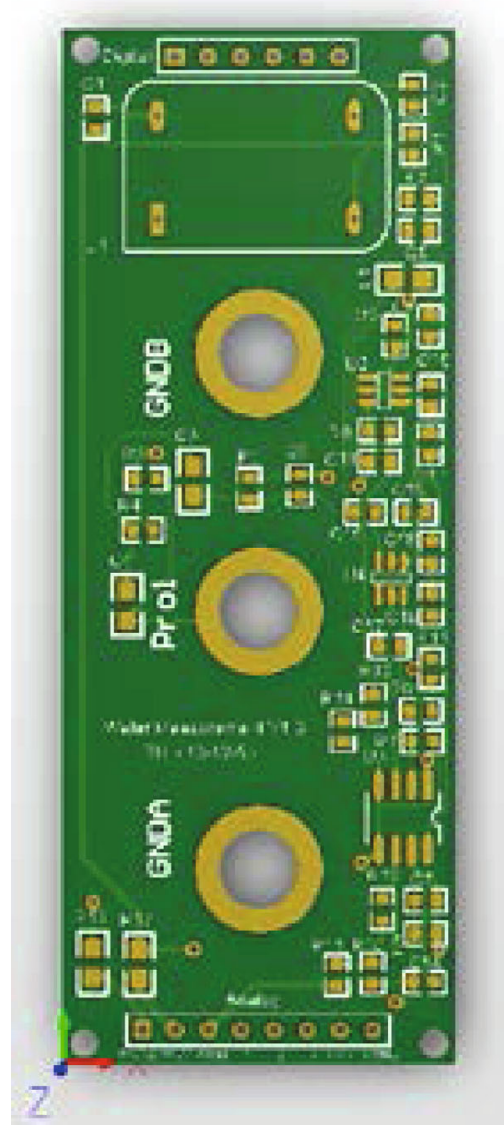

(b)

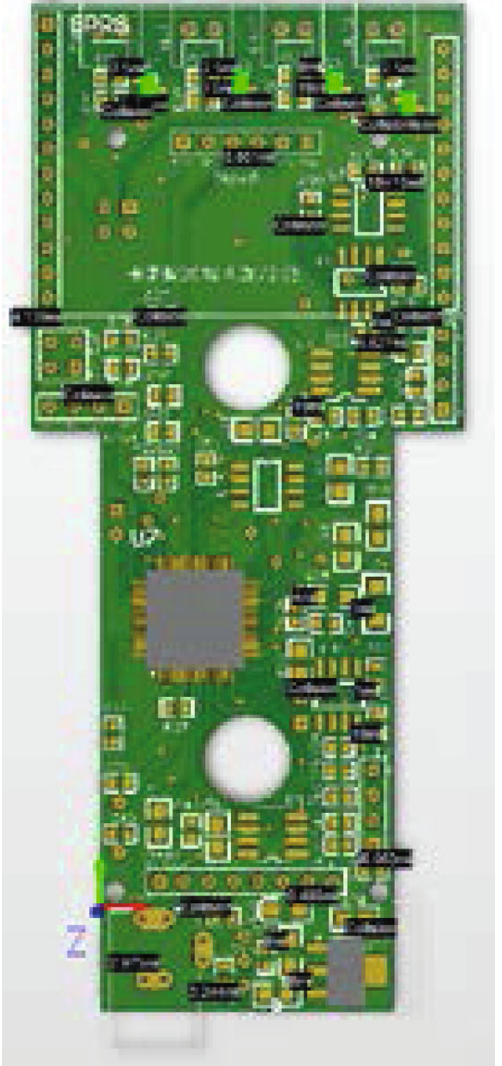

(c)

Figure 4: (a) Structure diagram of hardware system. (b) Printed circuit board of detection units. (c) Printed circuit board of collection units. 


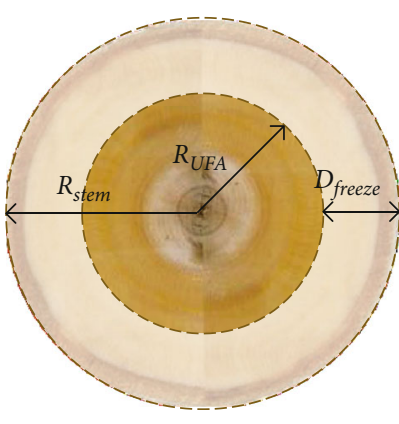

(a)

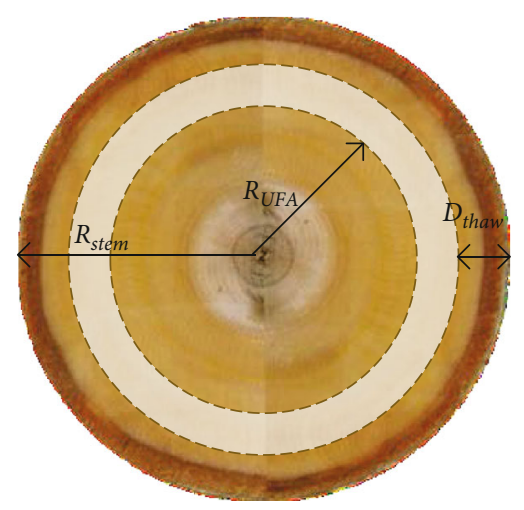

(b)
$R_{\text {stem }}$ : the radius of

stem segment

$R_{U F A}$ : the radius of

unfrozen area

$D_{\text {freeze }}$ : the freezing

depth of stem segment

$D_{\text {thaw }}$ : the thawing

depth of stem segment

FIgURE 5: (a) Freezing model of stem segment. (b) Thawing model of stem segment.

The thawing depth of stem segment can be calculated by solving Equation (13), and

$$
D_{\text {thaw }}=R_{\text {stem }}\left(1-\sqrt{\frac{\rho_{\text {ice }} \theta_{\text {ice }}}{\rho_{\text {liquid }} \theta_{\text {threshold }}}+\left(\frac{R_{\mathrm{UFA}}}{R_{\text {stem }}}\right)^{2}}\right) .
$$

The thawing velocity of stem segment $v_{\text {thaw }}$ was defined as the variation of $D_{\text {thaw }}$ per unit time. The indicator of thawing information can be calculated by

$$
v_{\text {thaw }}=\frac{\Delta D_{\text {thaw }}}{\Delta t},
$$

where $\Delta D_{\text {thaw }}$ is the variation of $D_{\text {thaw }}$ at the interval of $\Delta t$.

2.6. Calibration Experiments of the Compound Sensor. In order to obtain the functional relationships between output voltages of the compound sensor and two measured variables, the calibration experiments of stem temperature and water content were carried out separately. In the calibration experiment of stem temperature, the compound sensor was placed in the high-low temperature alternating test chamber (GDJ-1500B, HASUC, China, range: $-40 \sim 150^{\circ} \mathrm{C}$, accuracy: $\pm 0.1^{\circ} \mathrm{C}$ ) and the temperature of which increased evenly from -30 to $80^{\circ} \mathrm{C}$. Each temperature level lasted for half an hour. In the meanwhile, the temperature of the test chamber and the corresponding output voltage of the compound sensor were recorded. In the calibration experiment of stem water content, the fresh stem segment of Pachira glabra with $6 \mathrm{~cm}$ in diameter and $106 \mathrm{~cm}^{3}$ in volume was selected as the test sample. The diameter of the ring was adjusted to $6 \mathrm{~cm}$, and the length of the probe was customized to $15 \mathrm{~mm}$ which is close to the sapwood depth of test sample. Then, the stem segment connected with the compound sensor was placed in the blast drying oven (DHG-9030A, HASUC, China, range: $35 \sim 250^{\circ} \mathrm{C}$, accuracy: $\pm 0.5^{\circ} \mathrm{C}$ ) whose temperature was set at $45^{\circ} \mathrm{C}$. During the drying process, the mass of the stem segment and the corresponding output voltage of the compound sensor were recorded at the interval of 6 hours until the stem segment was thoroughly dried. Then, the records of stem mass were converted to the records of stem volumetric water content according to stem volume.

2.7. Freezing Experiments of the Solutions. In order to verify the technical feasibility of the compound sensor to detect the freezing point, the freezing experiments of the solutions with different freezing temperature were conducted separately. Considering that most of the freezable water in a plant crystallizes between 0 and $-4^{\circ} \mathrm{C}[18,19]$, the sodium chloride solutions with theoretical freezing temperature of 0 (mass concentration $0 \%$ ) and $-4^{\circ} \mathrm{C}$ (mass concentration 6.4\%) were selected as the test samples. Then, the plastic beaker filled with the solution was placed in the low-temperature refrigerator (DW-40W100, Haier, China, range: $-20 \sim-40^{\circ} \mathrm{C}$, accuracy: $\pm 1^{\circ} \mathrm{C}$ ) and connected with the compound sensor. During the freezing process, the temperature of the refrigerator was set at $-25^{\circ} \mathrm{C}$, and the output voltages of the compound sensor were recorded at the interval of 1 minute until the solution was thoroughly frozen.

2.8. Freeze-Thaw Experiments of the Plant Stem. In order to observe the freeze-thaw characteristics of the plant stem, the Pachira glabra with $6 \mathrm{~cm}$ in diameter $\left(R_{\mathrm{stem}}=3 \mathrm{~cm}\right)$ and $40 \mathrm{~cm}$ in height $\left(L_{\text {stem }}=40 \mathrm{~cm}\right)$ was selected as the test sample. The diameter of the ring was adjusted to $6 \mathrm{~cm}$, and the length of the probe was customized to $15 \mathrm{~mm}$ which is close to the sapwood depth of test sample. Then, the tree connected with the compound sensor was placed in the low-temperature refrigerator. In the freezing stage, the temperature of the refrigerator was set at $-25^{\circ} \mathrm{C}$, and this stage lasted for 550 minutes. In the thawing stage, the temperature of the refrigerator was consistent with room temperature (appr. $25^{\circ} \mathrm{C}$ ), and this stage lasted for 880 minutes. During the whole process, the output voltages of the compound sensor were recorded at the interval of 1 minute and converted to stem temperature and water content based on the acquired calibration functions which were described in Section 3.1. Finally, some freeze-thaw indicators including stem water content, ice content, freezing depth, freezing velocity, thawing depth, and thawing velocity were calculated based on the freeze-thaw model. 


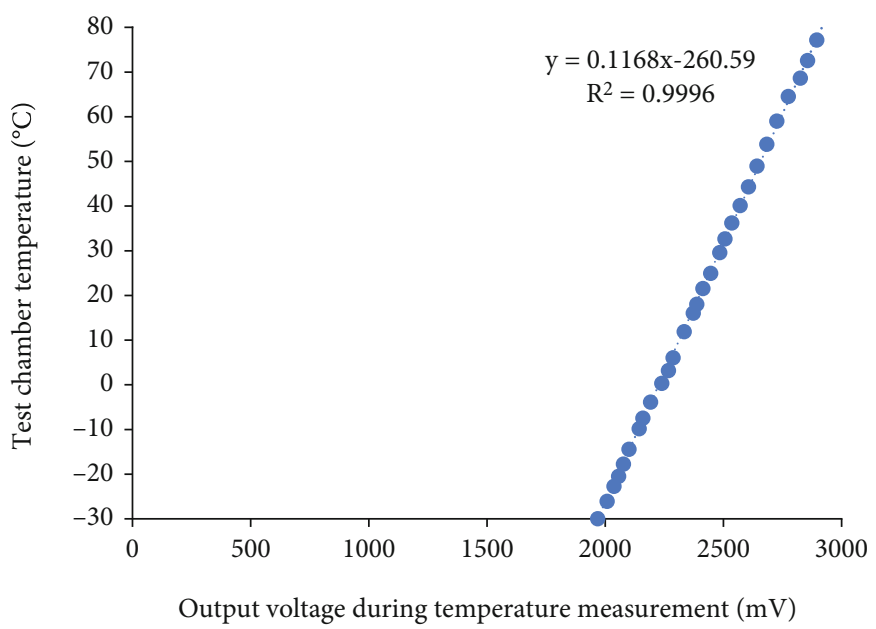

(a)

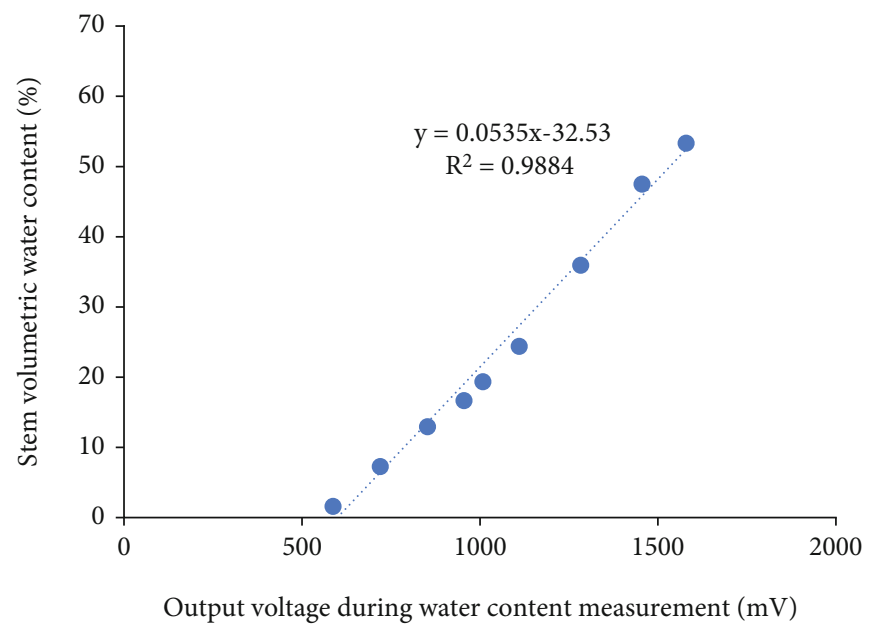

(b)

Figure 6: (a) Calibration equation of stem temperature. (b) Calibration equation of stem water content.

\section{Results and Discussion}

3.1. Calibration of Stem Temperature and Water Content. The calibration equations between output voltage and two measured variables are shown in Figure 6. As can be seen from Figure 6(a), the plot of test chamber temperature versus output voltage is a straight line with the slope of $0.1168^{\circ} \mathrm{CmV}^{-1}$ and the determination coefficient of 0.9996 . Combining the resolution of $\mathrm{A} / \mathrm{D}$ convertor mentioned above, the temperature resolution of the compound sensor can be calculated and it is less than $0.1^{\circ} \mathrm{C}$, indicating that the compound sensor is able to measure stem temperature with high sensitivity. In addition, two error indicators of temperature measurement were calculated based on the calibration equation. The mean absolute error (MAE) is approximately $0.57^{\circ} \mathrm{C}$, and the root mean square error (RMSE) is about $0.65^{\circ} \mathrm{C}$, revealing that the compound sensor has high measuring accuracy and stability in terms of stem temperature detection. As can be seen from Figure 6(b), there is a linear relation between stem volumetric water content and output voltage with the slope of $0.0535 \% \mathrm{mV}^{-1}$ and the determination coefficient of 0.9884 . Then, we calculated the volumetric water content resolution and two error indicators in the same way. The volumetric water content resolution of the compound sensor is less than $0.05 \%$, indicating that the compound sensor is able to measure stem volumetric water content with high sensitivity. The MAE and RMSE of volumetric water content measurement are approximately $1.59 \%$ and $1.81 \%$, respectively, revealing that the compound sensor has high measuring accuracy and stability in terms of stem water content detection. The calibration equations were used to observe solution freezing point and stem freeze-thaw characteristics in the next two sections.

3.2. Detection of Solution Freezing Point. The frozen temperature curves of sodium chloride solutions with theoretical freezing temperature of 0 and $-4^{\circ} \mathrm{C}$ are shown in Figure 7 in which the solution temperature is the calibrated value and the water content is directly the voltage value of sensor output. Before the solution temperature drops to the supercooling point $\left(-1.9^{\circ} \mathrm{C}\right.$ in Figure $7(\mathrm{a})$ and $-6.1^{\circ} \mathrm{C}$ in Figure $\left.7(\mathrm{~b})\right)$, the output voltage during water content measurement remains virtually unchanged. When the solution temperature breaks through the supercooling point and jumps to the freezing 


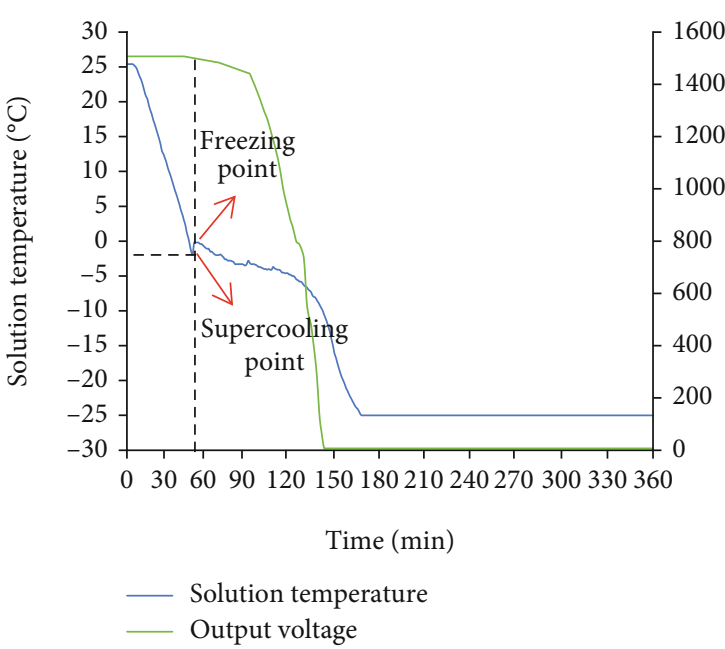

(a)

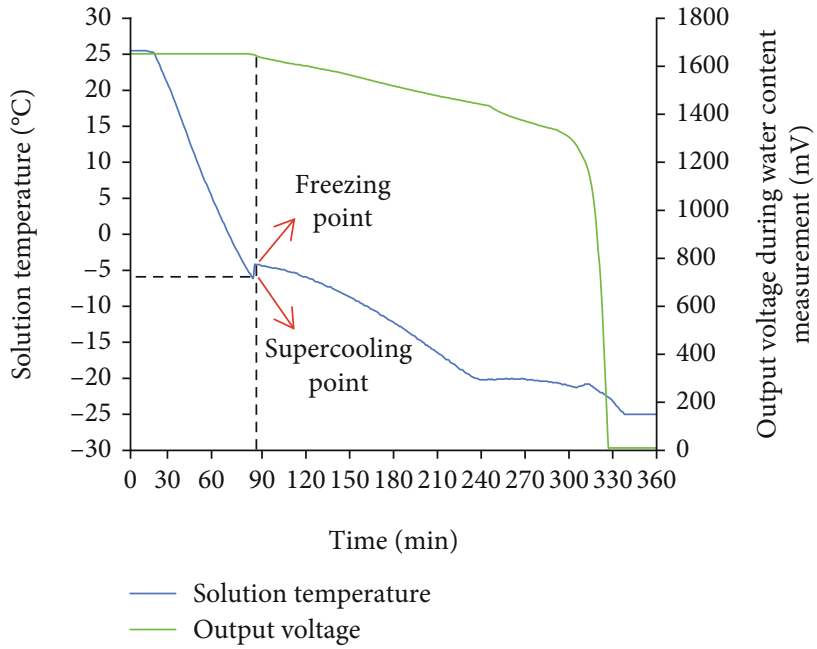

(b)

Figure 7: (a) Frozen temperature curve of sodium chloride solution with the freezing temperature of $0^{\circ} \mathrm{C}$. (b) Frozen temperature curve of sodium chloride solution with the freezing temperature of $-4^{\circ} \mathrm{C}$.

point $\left(-0.2^{\circ} \mathrm{C}\right.$ in Figure $7(\mathrm{a})$ and $-4.2^{\circ} \mathrm{C}$ in Figure $\left.7(\mathrm{~b})\right)$ under the effect of freezing latent heat [20], the output voltage during water content measurement begins to decline slowly due to the formation of ice crystals, indicating that the compound sensor is able to accurately detect solution freezing point based on latent heat effect. We assumed that the gradient of water content can be regarded as the freezing velocity of the solution. It can be concluded that during the freezing process of the solution, there exists a significant negative correlation between solution temperature and freezing velocity. It should be pointed out that the deficit of stem water content is related to various biotic and abiotic factors, such as insects, viruses, fungi, drought, salt, irradiation, and freezing stress [21, 22]. But the phenomenon of temperature jump from supercooling point to freezing point is a typical symbol of freezing stress, which can be used to determine the initial volumetric water content of stem at the beginning of the freezing process, namely $\theta_{\text {threshold }}$ in Formula (5).

3.3. Observation of Stem Freeze-Thaw Characteristics. The changes in stem volumetric water content, stem temperature, and temperature gradient during the freezing process are shown in Figure 8. As can be seen from Figure 8(a), the stem volumetric water content begins to decline at the point $\mathrm{A}$ (appr. $0.4^{\circ} \mathrm{C}$ ) which is the freezing point of stem tissue fluid. But comparing Figures 7 and 8, we do not observe the phenomenon of temperature jump from supercooling point to freezing point in stem. It is mainly caused by the fact that the thermal conductivity of wood is significantly smaller than that of water $[23,24]$. As can be seen from Figure 8(b), the stem temperature is relatively stable and the temperature gradient is less than $0.05^{\circ} \mathrm{C} \mathrm{mm}^{-1}$ during the period from point $\mathrm{A}$ to $\mathrm{B}$. It is mainly caused by the relative balance between ambient temperature and the release of latent heat during freezing process. Therefore, we can also determine the freezing point of stem by observing the temperature gradient. Considering that the place where the freezing started to take place may be outside the sensitive distance of the temperature probe, the mean temperature during the period from point $\mathrm{A}$ to $\mathrm{B}$ (appr. $-0.5^{\circ} \mathrm{C}$ ) can be regarded as the freezing temperature of stem tissue fluid. In the meanwhile, we can find that the stem temperature begins to drop rapidly during the period from point $\mathrm{B}$ (appr. $-1.9^{\circ} \mathrm{C}$ ) to the end. It is mainly caused by two factors. One is that the release of latent heat reduced with the decrease of freezing radius. The other is that the sensitivity of the temperature probe declined with the increase of freezing depth when the freezing depth exceeded half of the probe length $(7.5 \mathrm{~mm})$.

The changes in stem volumetric water content, stem temperature, and temperature gradient during the thawing process are shown in Figure 9. As can be seen from Figure 9(a), the stem volumetric water content begins to rise at the point $\mathrm{C}$ (appr. $-5.8^{\circ} \mathrm{C}$ ) which is the thawing point of stem tissue fluid. As can be seen from Figure 9(b), the stem temperature is relatively stable and the temperature gradient is less than $0.05^{\circ} \mathrm{C} \mathrm{mm}^{-1}$ during the period from point $\mathrm{C}$ to $\mathrm{D}$. It is mainly caused by the relative balance between ambient temperature and the absorption of latent heat during thawing process. Therefore, we can also determine the thawing point of the stem by observing the temperature gradient. Considering that the place where the thawing started to take place may be outside the sensitive distance of the temperature probe, the mean temperature during the period from point $\mathrm{C}$ to $\mathrm{D}$ (appr. $-2.3^{\circ} \mathrm{C}$ ) can be regarded as the thawing temperature of stem tissue fluid. In the meanwhile, we can find that the stem temperature begins to rise rapidly during the period from point $\mathrm{D}$ (appr. $-0.5^{\circ} \mathrm{C}$ ) to the end. It is mainly caused by two factors. One is that the absorption of latent heat reduced with the decrease of thawing radius. The other is that the sensitivity of the temperature probe declined with the increase of thawing depth when the thawing depth exceeded half of the probe length $(7.5 \mathrm{~mm})$. Comparing Figures 8 and 9 , we can observe that the thawing temperature of stem tissue fluid is significantly lower than the freezing temperature of 


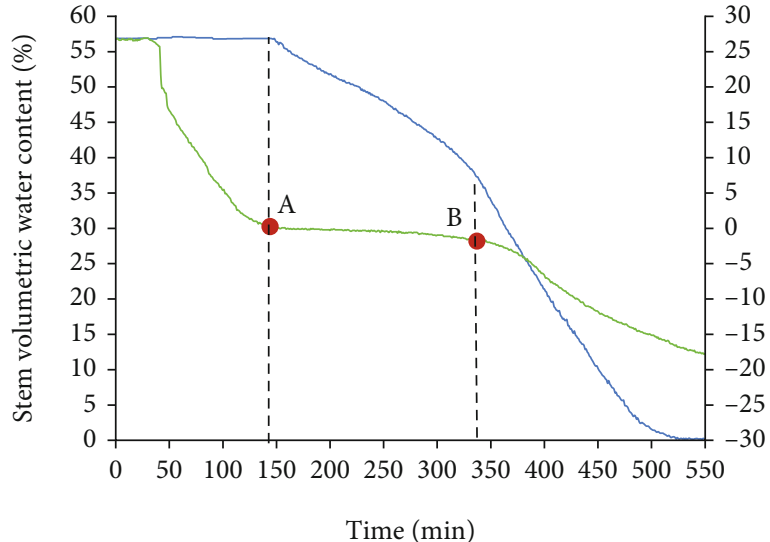

Stem volumetric water content Stem temperature

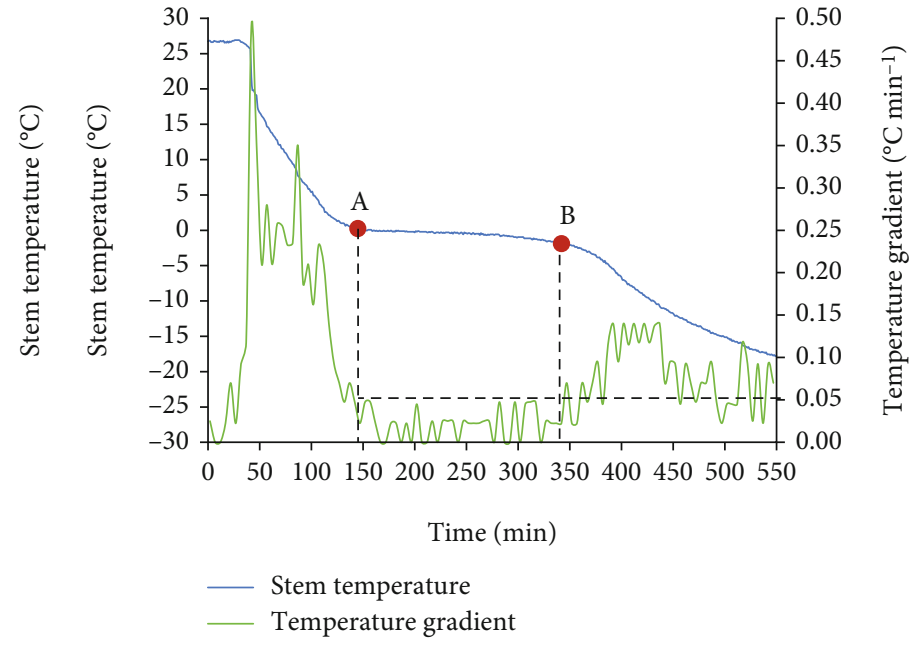

(b)

FIGURE 8: (a) Changes of stem volumetric water content and stem temperature during the freezing process. (b) Changes of stem temperature and temperature gradient during the freezing process.

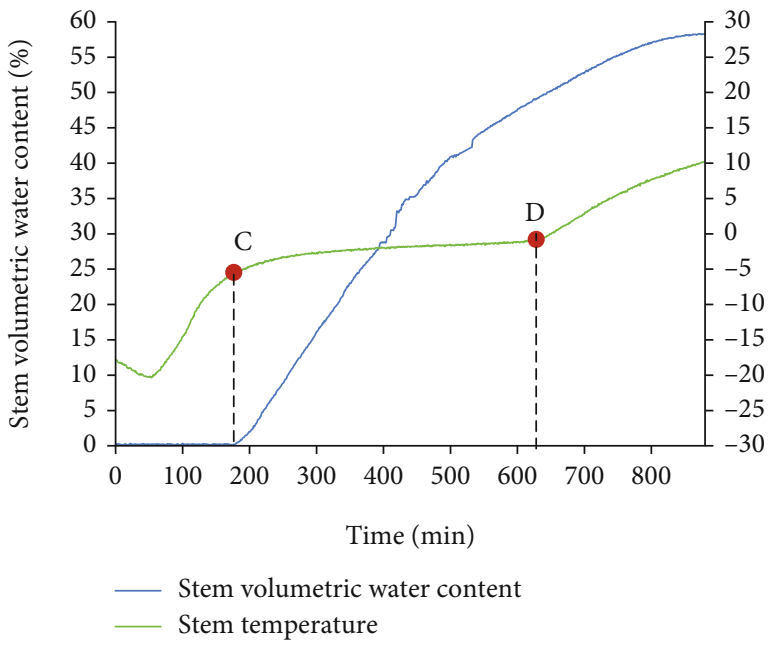

(a)

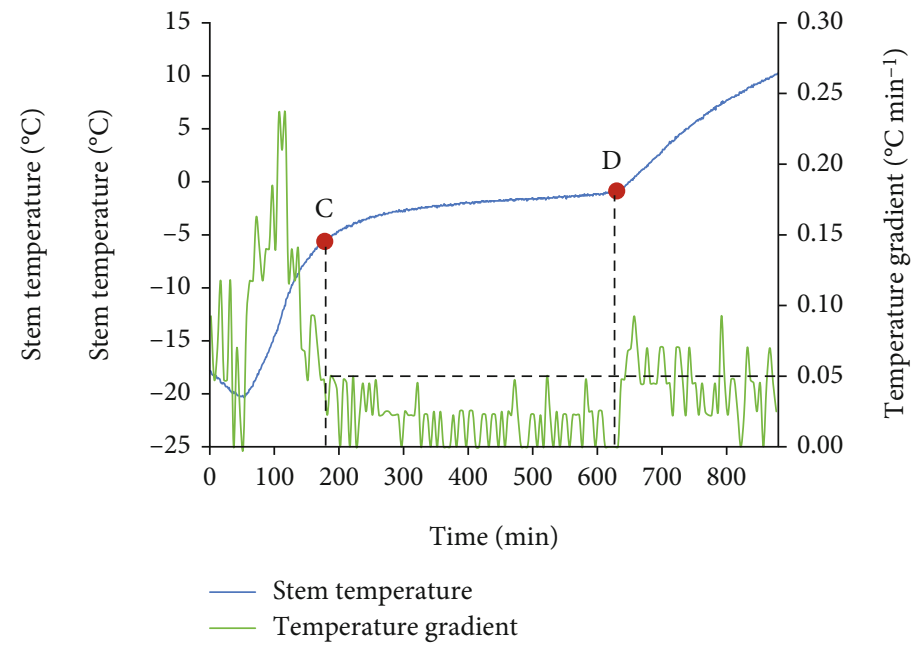

(b)

FIGURE 9: (a) Changes of stem volumetric water content and stem temperature during the thawing process. (b) Changes of stem temperature and temperature gradient during the thawing process.

stem tissue fluid. The reason is that some cytoplasmic components such as soluble sugars and electrolytes leaked out of cells during the freezing process, thus resulting in the decline of stem thawing temperature $[25,26]$.

The changes in stem volumetric water content and ice content during the freeze-thaw process are shown in Figure 10. As can be seen from Figure 10(a), the stem volumetric water content is $56.86 \%$ when the water began to freeze, namely $\theta_{\text {threshold }}=56.86 \%$, and the stem volumetric ice content is $63.01 \%$ when the water was completely frozen. The numerical difference between two indicators is due to the difference in density between water and ice. As can be seen from Figure 10(b), the stem volumetric water content is $58.27 \%$ which is slightly higher than $\theta_{\text {threshold }}$ when the ice was completely melted. It is mainly caused by the phenome- non that the moisture in the air condensed on the surface of stem water content electrodes, thus resulting in the increase of measured value. Comparing Figures 10(a) and 10(b), we can find that the duration of the freezing process (appr. 390 minutes) is shorter than that of the thawing process (appr. 624 minutes). It is mainly due to the fact that the thermal conductivity of ice is four times greater than that of water at the same temperature [27].

The changes in stem freeze-thaw depth and velocity during the freeze-thaw process are shown in Figure 11. As can be seen from Figure 11(a), there is a significant difference between the stem freezing velocity in sapwood and heartwood. When the freezing depth is less than $6 \mathrm{~mm}$, the mean freezing velocity is about $0.03 \mathrm{~mm} \mathrm{mim}^{-1}$. When the freezing depth is more than $6 \mathrm{~mm}$, the mean freezing velocity is about 


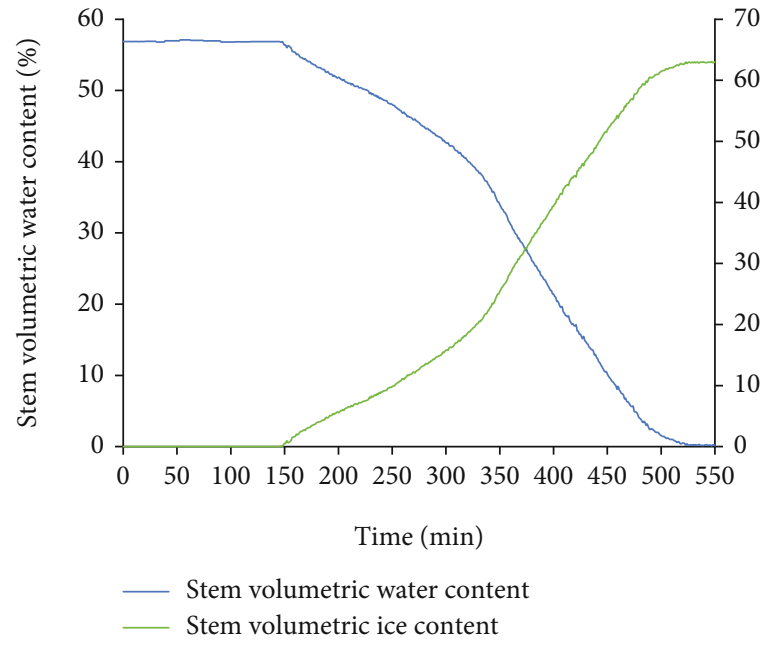

(a)

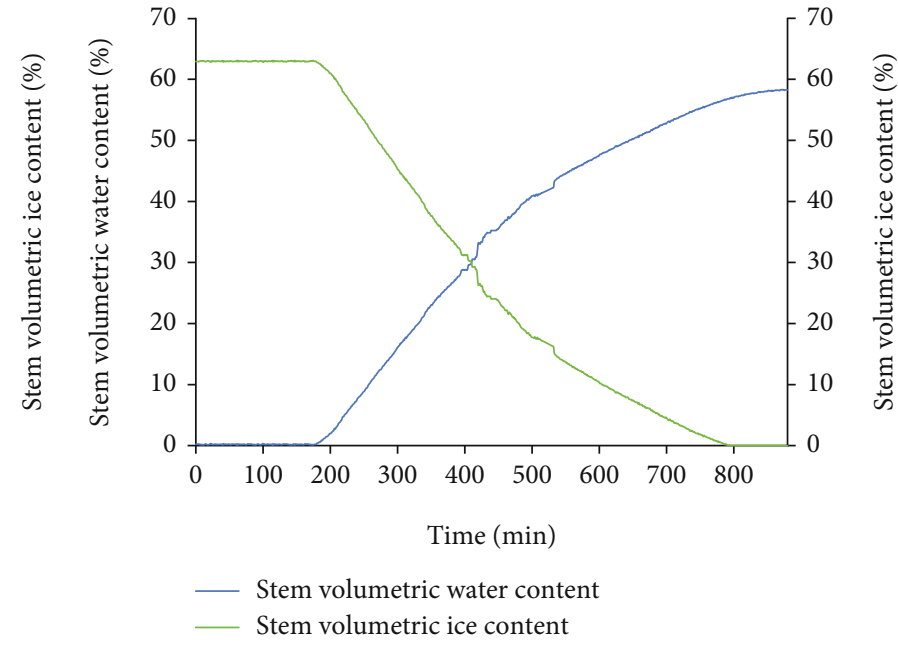

(b)

FIGURE 10: (a) Changes of stem volumetric water content and ice content during the freezing process. (b) Changes of stem volumetric water content and ice content during the thawing process.

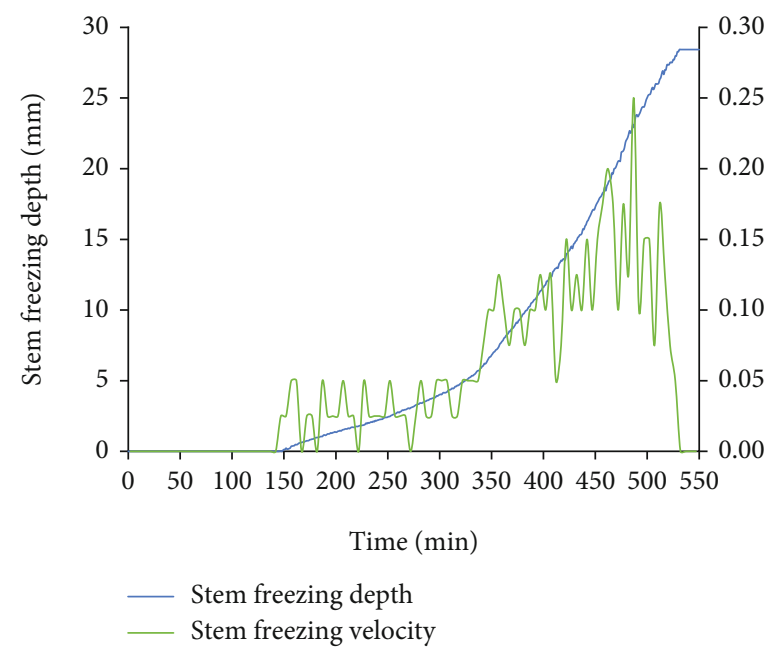

(a)

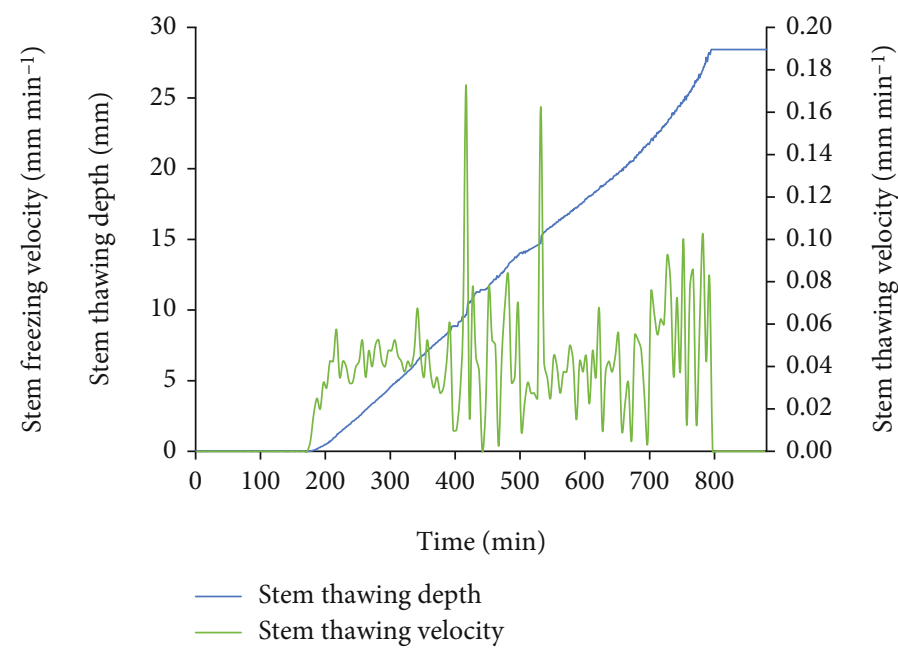

(b)

FIGURE 11: (a) Changes of stem freezing depth and velocity during the freezing process. (b) Changes of stem thawing depth and velocity during the thawing process.

$0.12 \mathrm{~mm} \mathrm{~min}^{-1}$. It is mainly due to the fact that the sapwood has some special pore structures including conduits and sieve tubes, thus causing the lower thermal conductivity in sapwood $[28,29]$. The maximum freezing depth calculated by the freeze-thaw model of plant stem is $28.43 \mathrm{~mm}$ which is slightly less than the stem radius. This error can be explained by the fact that the stem water content is not uniformly distributed in radial direction and the water content in sapwood is usually greater than that in heartwood [30]. Hence, the more accurate freeze-thaw model needs to be built in future work. As can be seen from Figure 11(b), there is no significant difference between the stem thawing velocity in sapwood and heartwood and the mean thawing velocity is about $0.04 \mathrm{~mm} \mathrm{mim}^{-1}$. It is mainly caused by the fact that ice masses can separate cell layers and create cavities which are distributed throughout sapwood and heartwood, thus causing the decrease of thermal conductivity in the whole stem $[31,32]$. The maximum thawing depth calculated by the freeze-thaw model of plant stem is still $28.43 \mathrm{~mm}$ which is equal to the maximum freezing depth, indicating that the model has high consistency in the freeze-thaw cycle.

\subsection{Performance Comparison between Conventional} Measurement Methods and the Compound Sensor. The conventional methods for detecting the freeze-thaw characteristics in plants can be divided into three categories: calorimetric method, spectrometric method, and electron microscopy. The differential scanning calorimetry is a typical calorimetric method and can quantify the amount of water that freezes or thaws. The amount of water which is frozen is determined by measuring the heat released during freezing process, or absorbed during thawing process, and by making calculations based on the heat of fusion of water and the heat capacities of ice and liquid water. The major weakness in 
using differential scanning calorimetry for determining ice content is in choosing the correct heat of fusion and heat capacity for stem tissue fluid. When most of the water in a stem is still liquid, it has a heat of fusion near that of pure water. As the amount of frozen water increases, such unfrozen water will have a high solute concentration, thus causing the decrease of the heat of fusion [33]. However, there is no appropriate method to measure the heat of fusion for stem tissue fluid in real time during freeze-thaw process. Ultimately, the uncertainty of the heat of fusion will greatly affect the measurement accuracy of differential scanning calorimetry. The compound sensor can measure stem water content with high accuracy by using the calibration equation and does not need to pay attention to the varying physicochemical indicators of stem tissue fluid during freeze-thaw process. Spectrometric method and electron microscopy can provide the distribution maps of liquid water and ice on the cross section of stem, respectively. But both methods require sampling and belong to destructive measurements. The compound sensor can realize in situ real-time measurement for water and ice content in the stem. Compared with the above three methods, the compound sensor has a better practical application value. However, the compound sensor has only a separate temperature probe which cannot accurately reveal the distribution and evolution of ice on the cross section of stem. Therefore, an ideal freeze-thaw model of plant stem was proposed to explain the freeze-thaw characteristics including stem water content, ice content, freezing depth, freezing velocity, thawing depth, and thawing velocity.

\section{Conclusions}

In order to explore the freeze-thaw characteristics of plant stem, a compound sensor for detecting stem temperature and water content in situ was designed and developed in this paper. The length of the temperature electrode and the diameter of the water content electrode can be customized to match different sizes of plant stems. The resolution, MAE, and RMSE of the compound sensor when measuring stem temperature are approximately $0.1,0.57$, and $0.65^{\circ} \mathrm{C}$, respectively. The resolution, MAE, and RMSE of the compound sensor when measuring stem water content are approximately $0.05,1.59$, and $1.81 \%$, respectively. Considering that the compound sensor cannot accurately reveal the distribution and evolution of ice on the cross section of stem, we proposed an ideal freeze-thaw model of plant stem based on the physicochemical properties of plant stem. Moreover, six freeze-thaw indicators including stem water content, ice content, freezing depth, freezing velocity, thawing depth, and thawing velocity were defined to describe the freeze-thaw characteristics of plant stem based on the compound sensor and the freeze-thaw model.

\section{Data Availability}

The data used to support the findings of this study are available from the corresponding author upon request.

\section{Conflicts of Interest}

The authors declare no conflicts of interest.

\section{Authors' Contributions}

For this research article, Chao Gao and Yandong Zhao conceived and designed the experiments; Hao Tian performed the experiments; Chao Gao and Hao Tian analyzed the data; Chao Gao wrote the paper.

\section{Acknowledgments}

This research was supported by the Beijing Natural Science Foundation (Grant No. 6214034), Fundamental Research Funds for Science and Technology Innovation Service Ability Construction (Grant No. PXM2020_014213_ 000017), National Key Research and Development Program of China (Grant No. 2017YFD0600901), and Beijing Municipal Science and Technology Commission (Grant No. Z161100000916012).

\section{References}

[1] M. J. Burke, L. V. Gusta, H. A. Quamme, C. J. Weiser, and P. H. Li, "Freezing and injury in plants," Annual Review of Plant Physiology, vol. 27, no. 1, pp. 507-528, 1976.

[2] R. S. Pearce, "Plant freezing and damage," Annals of Botany, vol. 87, no. 4, pp. 417-424, 2001.

[3] G. S. Sanghera, S. H. Wani, W. Hussain, and N. B. Singh, "Engineering cold stress tolerance in crop plants," Current Genomics, vol. 12, no. 1, pp. 30-43, 2011.

[4] J. Zhu, C. H. Dong, and J. K. Zhu, "Interplay between coldresponsive gene regulation, metabolism and RNA processing during plant cold acclimation," Current Opinion in Plant Biology, vol. 10, no. 3, pp. 290-295, 2007.

[5] C. B. Rajashekar and M. J. Burke, "Freezing characteristics of rigid plant tissues (development of cell tension during extracellular freezing)," Plant Physiology, vol. 111, no. 2, pp. 597603, 1996.

[6] L. V. Gusta, M. J. Burke, and A. C. Kapoor, "Determination of unfrozen water in winter cereals at subfreezing temperatures," Plant Physiology, vol. 56, no. 5, pp. 707-709, 1975.

[7] O. M. Lindstrom, N. P. A. Huner, and J. V. Carter, "Differential thermal analysis of the freezing of water in leaves of coldhardened and nonhardened Puma rye," Botanical Gazette, vol. 144, no. 2, pp. 234-239, 1983.

[8] R. V. Devireddy, D. Raha, and J. C. Bischof, "Measurement of water transport during freezing in cell suspensions using a differential scanning calorimeter," Cryobiology, vol. 36, no. 2, pp. 124-155, 1998.

[9] M. Wisniewski, S. E. Lindow, and E. N. Ashworth, "Observations of ice nucleation and propagation in plants using infrared video thermography," Plant Physiology, vol. 113, no. 2, pp. 327-334, 1997.

[10] M. Ishikawa, W. S. Price, H. Ide, and Y. Arata, "Visualization of freezing behaviors in leaf and flower buds of full-moon maple by nuclear magnetic resonance microscopy," Plant Physiology, vol. 115, no. 4, pp. 1515-1524, 1997.

[11] H. Ide, W. S. Price, Y. Arata, and M. Ishikawa, "Freezing behaviors in leaf buds of cold-hardy conifers visualized by 
NMR microscopy," Tree Physiology, vol. 18, no. 7, pp. 451458, 1998.

[12] S. Fujikawa and K. Kuroda, "Cryo-scanning electron microscopic study on freezing behavior of xylem ray parenchyma cells in hardwood species," Micron, vol. 31, no. 6, pp. 669686, 2000.

[13] S. Hillmer, C. Viotti, and D. G. Robinson, "An improved procedure for low-temperature embedding of high-pressure frozen and freeze-substituted plant tissues resulting in excellent structural preservation and contrast," Journal of Microscopy, vol. 247, no. 1, pp. 43-47, 2012.

[14] C. Gao, Y. Zhao, and Y. Zhao, "A novel sensor for noninvasive detection of in situ stem water content based on standing wave ratio," Journal of Sensors, vol. 2019, Article ID 3594964, 10 pages, 2019.

[15] V. M. Malygin, "Design of a platinum resistance thermometer temperature measuring transducer and improved accuracy of linearizing the output voltage," Measurement Techniques, vol. 38, no. 1, pp. 84-88, 1995.

[16] S. Roberts and A. Von Hippel, "A new method for measuring dielectric constant and loss in the range of centimeter waves," Journal of Applied Physics, vol. 17, no. 7, pp. 610-616, 1946.

[17] F. T. Ulaby and R. P. Jedlicka, "Microwave dielectric properties of plant materials," IEEE Transactions on Geoscience and Remote Sensing, vol. GE-22, no. 4, pp. 406-415, 1984.

[18] M. P. Fuller and P. L. Grice, "A chamber for the simulation of radiation freezing of plants," Annals of Applied Biology, vol. 133, no. 1, pp. 111-121, 1998.

[19] M. F. Thomashow, "Role of cold-responsive genes in plant freezing tolerance," Plant Physiology, vol. 118, no. 1, pp. 1-8, 1998.

[20] A. Gholaminejad and R. Hosseini, "A study of water supercooling," Journal of Electronics Cooling and Thermal Control, vol. 3, no. 1, pp. 1-6, 2013.

[21] A. Kadioglu, R. Terzi, N. Saruhan, and A. Saglam, "Current advances in the investigation of leaf rolling caused by biotic and abiotic stress factors," Plant Science, vol. 182, pp. 42-48, 2012.

[22] P. E. Verslues, M. Agarwal, S. Katiyar-Agarwal, J. Zhu, and J. K. Zhu, "Methods and concepts in quantifying resistance to drought, salt and freezing, abiotic stresses that affect plant water status," The Plant Journal, vol. 45, no. 4, pp. 523-539, 2006.

[23] J. Zhou, H. Zhou, C. Hu, and S. Hu, "Measurements of thermal and dielectric properties of medium density fiberboard with different moisture contents," BioResources, vol. 8, no. 3, pp. 4185-4192, 2013.

[24] E. Troppová, M. Švehlík, J. Tippner, and R. Wimmer, "Influence of temperature and moisture content on the thermal conductivity of wood-based fibreboards," Materials and Structures, vol. 48, no. 12, pp. 4077-4083, 2015.

[25] J. Klotke, J. Kopka, N. Gatzke, and A. G. Heyer, "Impact of soluble sugar concentrations on the acquisition of freezing tolerance in accessions of Arabidopsis thaliana with contrasting cold adaptation-evidence for a role of raffinose in cold acclimation," Plant, Cell and Environment, vol. 27, no. 11, pp. 1395-1404, 2004.

[26] M. E. S. Nunes and G. R. Smith, "Electrolyte leakage assay capable of quantifying freezing resistance in rose clover," Crop Science, vol. 43, no. 4, pp. 1349-1357, 2003.
[27] E. J. Rosenbaum, N. J. English, J. K. Johnson, D. W. Shaw, and R. P. Warzinski, "Thermal conductivity of methane hydrate from experiment and molecular simulation," The Journal of Physical Chemistry B, vol. 111, no. 46, pp. 13194-13205, 2007.

[28] T. Hölttä, M. Mencuccini, and E. Nikinmaa, "Linking phloem function to structure: Analysis with a coupled xylem-phloem transport model," Journal of Theoretical Biology, vol. 259, no. 2, pp. 325-337, 2009.

[29] S. D. Wullschleger, K. W. Childs, A. W. King, and P. J. Hanson, "A model of heat transfer in sapwood and implications for sap flux density measurements using thermal dissipation probes," Tree Physiology, vol. 31, no. 6, pp. 669-679, 2011.

[30] J. H. Fromm, I. Sautter, D. Matthies, J. Kremer, P. Schumacher, and C. Ganter, "Xylem water content and wood density in spruce and oak trees detected by high-resolution computed tomography," Plant Physiology, vol. 127, no. 2, pp. 416-425, 2001.

[31] J. Farrant, C. A. Walter, H. Lee, and L. E. McGann, "Use of two-step cooling procedures to examine factors influencing cell survival following freezing and thawing," Cryobiology, vol. 14, no. 3, pp. 273-286, 1977.

[32] M. E. McCully, M. J. Canny, and C. X. Huang, “The management of extracellular ice by petioles of frost-resistant herbaceous plants," Annals of Botany, vol. 94, no. 5, pp. 665-674, 2004.

[33] M. J. Burke, R. G. Bryant, and C. J. Weiser, "Nuclear magnetic resonance of water in cold acclimating red osier dogwood stem," Plant Physiology, vol. 54, no. 3, pp. 392-398, 1974. 